\title{
Qualidade de vida relacionada à saúde dos cuidadores formais de idosos institucionalizados em Natal, Rio Grande do Norte
}

\author{
Lara de Melo Barbosa* \\ Kenya Noronha** \\ Maria Helena Constantino Spyrides ${ }^{* \star *}$ \\ Cristiane Alessandra Domingos de Araújo ${ }^{\star \star \star \star}$
}

\begin{abstract}
O Brasil vem experimentando um processo de envelhecimento populacional que impõe desafios para atender às necessidades dos idosos, especialmente os dependentes funcionais. Nesse cenário, as instituições de longa permanência para idosos (ILPI) podem ser importantes para prover auxílio e amparo a esse grupo populacional e seus familiares. 0 objetivo desse estudo é caracterizar o perfil do cuidador de idosos institucionalizados em ILPI, abordando especificamente a qualidade de vida relacionada à saúde mensurada pelo instrumento SF- 36 . Foi também analisado o perfil sociodemográfico e ocupacional desses indivíduos. Os dados provêm de uma pesquisa realizada em 2012 entre os cuidadores formais ocupados em 11 das 12 ILPI cadastradas em Natal, RN. Foram entrevistados 92 cuidadores formais, representando $68 \%$ do universo desse grupo ocupacional. Realizaram-se análises descritivas do perfil do cuidador, distinguindo-se por natureza da ILPI (filantrópica ou privada), bem como testes estatísticos para verificar se as diferenças segundo a natureza das instituições eram significativas. A maior perda de saúde foi observada para o domínio "estado de saúde geral”, seguido pelos domínios vitalidade e de dor, definidos pelo SF-36. A perda de saúde pode refletir, em certa medida, a sobrecarga de trabalho imposta aos cuidadores, em relação tanto à jornada de trabalho como ao elevado número de idosos sob a responsabilidade de cada cuidador. Não foram observadas diferenças significativas na qualidade de vida relacionada à saúde segundo natureza das instituições.
\end{abstract}

Palavras-chave: Envelhecimento. Cuidador formal de idosos. Instituições de longa permanência para idosos. SF-36. Qualidade de vida relacionada à saúde.

\footnotetext{
* Universidade Federal do Rio Grande do Norte (UFRN), Centro de Ciências Exatas e da Terra (CCET), Departamento de Ciências Atmosféricas e Climáticas (DCAC), Natal-RN, Brasil (lara@ccet.ufrn.br).

** Universidade Federal de Minas Gerais (UFMG), Faculdade de Ciências Econômicas (Face), Departamento de Economia, Belo Horizonte-MG, Brasil (knoronha@cedeplar.ufmg.br).

${ }^{* \star *}$ Universidade Federal do Rio Grande do Norte (UFRN), Centro de Ciências Exatas e da Terra (CCET), Departamento de Ciências Atmosféricas e Climáticas (DCAC), Natal-RN, Brasil (spyrides@ccet.ufrn.br).

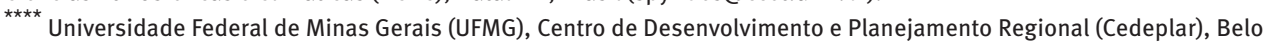
Horizonte-MG, Brasil (cristianeales@yahoo.com.br).
} 
Barbosa, L.M. et al. Qualidade de vida relacionada à saúde dos cuidadores formais de idosos institucionalizados...

\section{Introdução}

0 aumento da longevidade e o envelhecimento populacional são realidades vivenciadas por diversos países. No entanto, a forma e a velocidade com que esses processos vêm ocorrendo dependem de cada sociedade. Enquanto nos países mais desenvolvidos o processo de envelhecimento populacional encontra-se em um estágio mais avançado, naqueles em desenvolvimento, incluindo o Brasil, esse fenômeno ocorre relativamente em um período recente e de forma mais acelerada (WONG; CARVALHO, 2006; BRITO, 2007; ALVES, 2008; VERAS, 2009, 2003; CAMARANO; PASSINATO, 2004; PALLONI et al., 2005; PALLONI et al., 2006). Essas diferenças na velocidade do processo de envelhecimento têm implicações quanto ao tempo de adaptação e reorganização das instituições e políticas para responder às demandas da população idosa. Dessa forma, o desafio imposto às sociedades menos desenvolvidas tem sido maior diante dessas mudanças. Independentemente do nível de desenvolvimento econômico, as alterações na estrutura etária, com o consequente aumento do peso relativo da população idosa, são profundas e irreversíveis (VERAS, 2009; BRITO, 2007). Tal fenômeno decorre de reduções nas taxas de fecundidade e de mortalidade, sobretudo a mortalidade infantil (WONG; CARVALHO, 2006; BRITO, 2007; ALVES, 2008; PALLONI et al., 2006; CAMARANO et al., 2004a). Mais recentemente, ganhos na longevidade têm sido também atribuídos a reduções nas taxas de mortalidade em idades mais avançadas (TURRA, 2012; GONZAGA, 2014).

0 processo de envelhecimento requer formulação de políticas públicas adequadas para atender às necessidades desse grupo populacional, principalmente nos setores da previdência, assistência social e saúde. Especificamente na área de saúde, à medida que a idade avança ocorrem transformações na capacidade física, cognitiva e mental, atingindo o maior grau na velhice. Nesse cenário, os idosos necessitam de cuidados cada vez mais constantes para a realização de suas atividades diárias (MORAES, 2012). 0 papel de um cuidador capacitado torna-se essencial na tarefa de propiciar uma velhice com maior dignidade e menor percepção de suas limitações funcionais. Esses cuidados, conhecidos como cuidados de longa duração, compreendem um conjunto de serviços prestados a indivíduos dependentes, ou seja, que apresentam limitações para realizar atividades da vida diária, tais como comer, tomar banho, ir ao banheiro, preparar refeições, manusear o próprio dinheiro e fazer compras. Esses serviços englobam desde ajuda material até apoio emocional e instrumental (CAMARANO; MELLO, 2010; SAAD, 2004). Embora os cuidados de longa duração sejam ofertados a indivíduos de todas as idades, as características de morbidade dos idosos os tornam os maiores demandantes desse tipo de auxílio (CAMARANO; MELLO, 2010; CAMARGOS, 2014).

A organização da oferta do cuidado ao idoso depende do modelo adotado pelos países. Em linhas gerais, são observados três principais modelos de cuidado de longa duração que variam de acordo com a principal instituição prestadora e financiadora desses cuidados. 0 primeiro, adotado nos países escandinavos, Japão, Canadá e Austrália, caracteriza-se pelo 
papel central do Estado. No segundo modelo, o mercado provê a maior parte dos cuidados, especialmente por sistemas de seguros privados, sendo observado principalmente nos Estados Unidos. 0 terceiro é aquele em que a família constitui a principal provedora desses cuidados. Esse modelo é adotado em alguns países europeus, tais como Itália, Espanha, Portugal e Grécia, e na maioria dos países latino-americanos, incluindo o Brasil (BATISTA, et al., 2008; CAMARANO et al., 2004b; SAAD, 2004; CAMARANO; MELLO, 2010; CARVALHO, 2009). 0 cuidado é prestado por meio de um cuidador informal, no ambiente domiciliar por um familiar, em geral mulheres, sem qualificação adequada para a realização dessas atividades, não envolvendo remuneração (CAMARANO; MELLO, 2010). 0 modelo baseado na família foi social e culturalmente construído, sendo que o não provimento desses serviços tende a gerar sentimentos de abandono e negligência por parte tanto dos idosos como dos familiares. Esse modelo implica a verticalização dos arranjos domiciliares e acarreta custos emocionais, psicológicos e financeiros para as famílias (CAMARANO et al., 2004b; CAMARANO; MELLO, 2010).

O crescimento acentuado da população idosa e a menor disponibilidade de cuidadores familiares, devido principalmente à redução do número de filhos e maior inserção feminina no mercado de trabalho, vêm ameaçando fortemente esse modelo de cuidados baseado na família (PASSINATO; KORNIS, 2009; SAAD, 2004). Em decorrência do processo de envelhecimento populacional e da consequente diminuição de potenciais cuidadores informais, a expansão da provisão de cuidados de longa duração por meio de instituições tem assumido posição importante (RIPSA, 2009; CAMARGOS, 2014). No Brasil, historicamente as instituições de cuidado ao idoso eram conhecidas como asilos, termo comumente associado pela sociedade a situações negativas e preconceituosas e de rejeição dos idosos pelas famílias. Contudo, a evidente redução da disponibilidade do tradicional cuidado familiar aponta para maiores demandas de cuidados formais. Nesse contexto, os modelos alternativos de cuidados a idosos revelam-se grandes aliados (PASSINATO; KORNIS, 2009; DAVIM et al., 2004; CAMARANO et al., 2010, CAMARGOS, 2014). Mais recentemente, tem havido um esforço por parte da sociedade e do Estado em alterar a percepção negativa sobre a institucionalização dos idosos, que se mostra em muitas ocasiões uma alternativa de cuidado mais segura e de maior socialização entre as pessoas dessa faixa de idade (CHRISTOPHE; CAMARANO, 2010; ALVES-SILVA et al., 2013). Uma mudança importante é a própria denominação dessas instituições, que passaram a ser conhecidas como instituições de longa permanência para idosos (ILPI), tal como sugerido pela Sociedade Brasileira de Geriatria e Gerontologia (PINTO; SIMSON, 2012). Essa alteração, que não é meramente uma discussão semântica, reflete a nova função que essas instituições desempenham em relação ao cuidado prestado ao idoso (CAMARANO; KANSO, 2010).

No ato de cuidar, a atenção, em geral, se volta para o idoso, devido à sua fragilidade e, muitas vezes, à sua condição de dependência que o deixa vulnerável. A atuação dos cuidadores formais dessas instituições tem assumido cada vez mais um espaço importante nessa atual realidade vivenciada pela sociedade brasileira. Um avanço recente na literatura 
nacional tem como marco o estudo realizado por Camarano e Kanso (2010), que avaliaram as características das ILPI, ressaltando aspectos associados a infraestrutura, recursos financeiros e humanos disponíveis, fontes de financiamento, serviços oferecidos e algumas características dos idosos institucionalizados. Essa pesquisa teve caráter censitário, sendo realizada em todo o território nacional no período entre 2007 e 2009. Apesar de sua importância e pioneirismo no Brasil, não foi objeto do censo institucional caracterizar o perfil dos cuidadores das ILPI. Os estudos que investigam o perfil desses cuidadores no Brasil são escassos e em geral produzem análises qualitativas (MEDEIROS et al., 2015; MEDEIROS, 2014; ARAÚJO et al., 2014, RIBEIRO et al., 2008, 2009; COUTO, 2012). A maior parte da literatura analisa as características dos cuidadores informais e formais que atuam no ambiente domiciliar (GARRIDO; MENEZES, 2004; SIMONETTI; FERREIRA, 2008; POLLO; ASSIS, 2008; CAMARANO, 2008a; SANTOS; PAVARINI, 2010; PEREIRA et al., 2013; KAWASAKI; DIOGO, 2001a, 2001b). A escassez de pesquisas específicas para o cuidador formal das ILPI reflete a própria estrutura desse tipo de assistência ao idoso no país, em que predomina o cuidado exercido por um familiar.

Recentemente, foi realizada uma pesquisa no município de Natal para caracterizar o perfil socioeconômico e a formação profissional do cuidador de idosos institucionalizados. 0 estudo identificou um total de 14 ILPI existentes em Natal, das quais nove concordaram em participar da pesquisa. Foram entrevistados 63 do total de 83 cuidadores empregados nessas nove ILPI. Os resultados mostraram um perfil socioeconômico baixo e fragilidade na formação do cuidador no município (SILVA et al., 2016).

O objetivo desse artigo é caracterizar o perfil do cuidador de idosos institucionalizados, abordando especificamente a qualidade de vida relacionada à saúde. Foram contemplados os aspectos tanto físicos como mentais mensurados por meio do instrumento SF-36 (Medical Outcomes Study 36-Item Short-Form Health Survey), traduzido para o português, adaptado e validado por Ciconelli et al. (1999). Além dessas características, incluem-se variáveis socioeconômicas e demográficas dos cuidadores e alguns aspectos das condições de trabalho. A análise é realizada para o total dos entrevistados, segundo a natureza da ILPI (filantrópica e privada). A fonte de informações provém de uma pesquisa realizada em 2012 entre os cuidadores formais ocupados nas ILPI existentes no município de Natal, Rio Grande do Norte (RN).

A preocupação em entender as características associadas à qualidade de vida relacionada à saúde dos cuidadores formais das ILPI é primordial, pois se, por um lado, afetam diretamente a qualidade no cuidado prestado, por outro, pode haver perdas consideráveis no estado de saúde físico e mental dos profissionais envolvidos no cuidado de idosos (BARTOLO et al., 2010; MOLYNEUX et al., 2008; CAMARGOS, 2014; CHAN et al., 2013; ARAI et al., 2014; LOUREIRO et al., 2013). Portanto, o presente estudo se constitui em um avanço importante na medida em que se torna possível identificar as características de saúde associadas a esses profissionais. Como a realização dessas atividades envolve grande esforço físico e mental, os danos sobre a saúde dos cuidadores precisam ser analisados 
Barbosa, L.M. et al. Qualidade de vida relacionada à saúde dos cuidadores formais de idosos institucionalizados...

de forma a auxiliar no desenvolvimento de políticas e regulamentação dessa ocupação, que foi reconhecida pelo Ministério do Trabalho por meio da Classificação Brasileira de Ocupação desde 2003, sendo definidas as atividades a serem desempenhadas pela categoria. Em 17 de outubro de 2012, foi aprovado pelo Senado o Projeto de Lei 284/2011 que regulamenta a profissão de cuidador do idoso, definindo sua atuação profissional e a qualificação necessária. Em novembro de 2012, o PL 284/2011 foi encaminhado para a Câmara dos Deputados, recebendo o número 4702/2012 (RIBEIRO, 2015), e desde 14 de março de 2013 encontra-se na Comissão de Seguridade Social e Família (CFSS) aguardando tramitação na Câmara dos Deputados para posterior aprovação presidencial (RIBEIRO, 2015). 0 desenvolvimento de estudos que buscam conhecer o perfil demográfico, de saúde e das condições de trabalho desses cuidadores é fundamental, pois fornece subsídios para orientar a formulação de políticas direcionadas a esses trabalhadores, além de pontuar a importância de se concretizar o processo de regulamentação, ainda em curso no país, dessa nova classe laboral.

\section{Material e métodos}

\section{Material}

Foram entrevistados cuidadores formais empregados nas ILPI localizadas no município de Natal-RN. As entrevistas ocorreram entre 01 de outubro e 30 de novembro de 2012 por dois entrevistadores treinados pelos pesquisadores principais do estudo. Em Natal, em 2011, havia 14 ILPI cadastradas pela Secretaria Municipal de Saúde de Natal e pelo Conselho Municipal do Idoso de Natal. Dessas, 11 concordaram em participar da pesquisa, das quais seis (55\%) eram registradas como privadas com fins lucrativos e cinco (45\%) como filantrópicas. As três ILPI que se recusaram a participar eram de natureza filantrópica. Nas 11 ILPI participantes, estavam empregados 121 cuidadores, conforme declarado pelos dirigentes dessas instituições. Desse total, 92 (76\%) foram entrevistados, pois $28(23,2 \%)$ estavam em período de férias ou em gozo de licença de qualquer natureza e apenas um cuidador $(0,8 \%)$ se recusou a participar da pesquisa. Antes do levantamento de campo, os questionários foram testados em uma amostra piloto composta por $10 \%$ do total de cuidadores pertencentes a uma ILPI, previamente sorteada.

0 instrumento de coleta foi composto por duas seções que se referiam ao perfil sociodemográfico e à qualidade de vida em saúde do cuidador formal de idosos institucionalizados. Os atributos investigados contemplaram aspectos demográficos (sexo, idade, situação conjugal, quantidade de filhos vivos, religião e cor autodeclarada), socioeconômicos (nível de escolaridade, se estava estudando no momento da entrevista e renda familiar) e ocupacionais (se o trabalho de cuidador era sua principal fonte de renda, satisfação em cuidar dos idosos na instituição, principal motivo que o fez exercer a atividade de cuidador, número de anos que exerce essa profissão independentemente do local em que atuava, quantidade de idosos que cuida na instituição, realização de curso específico para 
cuidador, carga horária, vínculo empregatício, se pensou em algum momento em deixar de ser cuidador de idoso e o motivo).

Para avaliação da qualidade de vida em saúde do cuidador formal, utilizou-se o questionário SF-36 (Medical Outcomes Study 36-Item Short-Form Health Survey), traduzido para o português, adaptado e validado por Ciconelli et al. (1999). O SF-36 é um instrumento genérico multidimensional que avalia diferentes aspectos relacionados à saúde, sendo considerado de fácil aplicação e compreensão (ADORNO; BRASIL-NETO, 2013; PINTO et al., 2009). 0 instrumento é composto por 36 questões englobando oito domínios: capacidade funcional (dez itens); aspectos físicos (quatro itens); dor (dois itens); estado geral da saúde (cinco itens); vitalidade (quatro itens); aspectos sociais (dois itens); aspectos emocionais (três itens); e saúde mental (cinco itens). Além dos oito domínios, há uma avaliação comparativa entre as condições de saúde atual e aquelas de um ano atrás (um item). 0 instrumento fornece um índice para cada domínio com escore final variando de zero a 100, obtido por meio de cálculo do Raw Scale, representando, respectivamente, o pior e o melhor estado de saúde (WARE; SHERBOURNE, 1992; CICONELLI et al., 1999).

A pesquisa foi aprovada pelo Comitê de Ética em Pesquisa da Universidade Federal do Rio Grande do Norte - Parecer no 125.756, em 28 de setembro de 2012.

\section{Métodos}

Realizaram-se análises descritivas do perfil do cuidador, segundo a natureza da ILPI (filantrópica ou privada). Para verificar se as diferenças são estatisticamente diferentes conforme a natureza da ILPI, aplicaram-se o teste de associação $X^{2}$ de Pearson para variáveis categorizadas e o teste $t$-Student para as variáveis contínuas. Especificamente para a análise da qualidade de vida mensurada por meio do SF-36, como a distribuição dos índices calculados para cada um dos oito domínios não teve aderência à curva normal, utilizou-se o teste não paramétrico $U$ de Mann Whitney.

\section{Resultados}

A Tabela 1 apresenta as características demográficas e socioeconômicas dos cuidadores de idosos institucionalizados no município de Natal em 2012, segundo a natureza da ILPI. Considerando o total dos cuidadores entrevistados, observou-se que a maior parte era do sexo feminino (85\%), com idade acima de 30 anos (73\%) e de cor parda (64\%). Em relação à situação familiar, $61 \%$ eram casados ou unidos e $51 \%$ possuíam dois ou mais filhos. $A$ maioria dos entrevistados se declarou católica (64\%) e com renda familiar mensal de 1 a 3 salários mínimos (95\%). Em torno de $42 \%$ reportaram ter nível de instrução inferior ao ensino médio completo e apenas 4,4\% declararam possuir pelo menos um ano de ensino superior.

Do total dos cuidadores entrevistados, 34\% trabalhavam nas ILPI de natureza privada e $66 \%$ nas de natureza filantrópica. A análise das características sociodemográficas dos cuidadores segundo natureza da ILPI mostrou diferenças significativas a $10 \%$ no que se refere a sexo, idade, quantidade de filhos, nível de instrução e renda familiar. 0 perfil dos 
Barbosa, L.M. et al. Qualidade de vida relacionada à saúde dos cuidadores formais de idosos institucionalizados...

cuidadores das instituições filantrópicas foi caracterizado por um peso relativamente mais elevado de profissionais do sexo masculino (20\% contra $6,5 \%$ nas ILPI privadas), com idade mais avançada, possuindo um número maior de filhos e escolaridade mais baixa. Enquanto nas ILPI filantrópicas $44 \%$ dos cuidadores possuíam 40 anos ou mais de idade, nas privadas esse percentual correspondia a 19\%. Nessas últimas, a contribuição dos profissionais com 20 a 29 anos era maior (42\%). Em relação ao nível de instrução, nas ILPI filantrópicas verificou-se um predomínio de cuidadores com até o ensino médio incompleto ( $51 \%$ contra $26 \%$ nas privadas), enquanto nas privadas observou-se um peso maior dos que já possuíam ensino médio completo (71\%).

TABELA 1

Cuidadores formais de idosos das ILPI, por natureza da instituição, segundo variáveis demográficas e socioeconômicas

Município de Natal - 2012

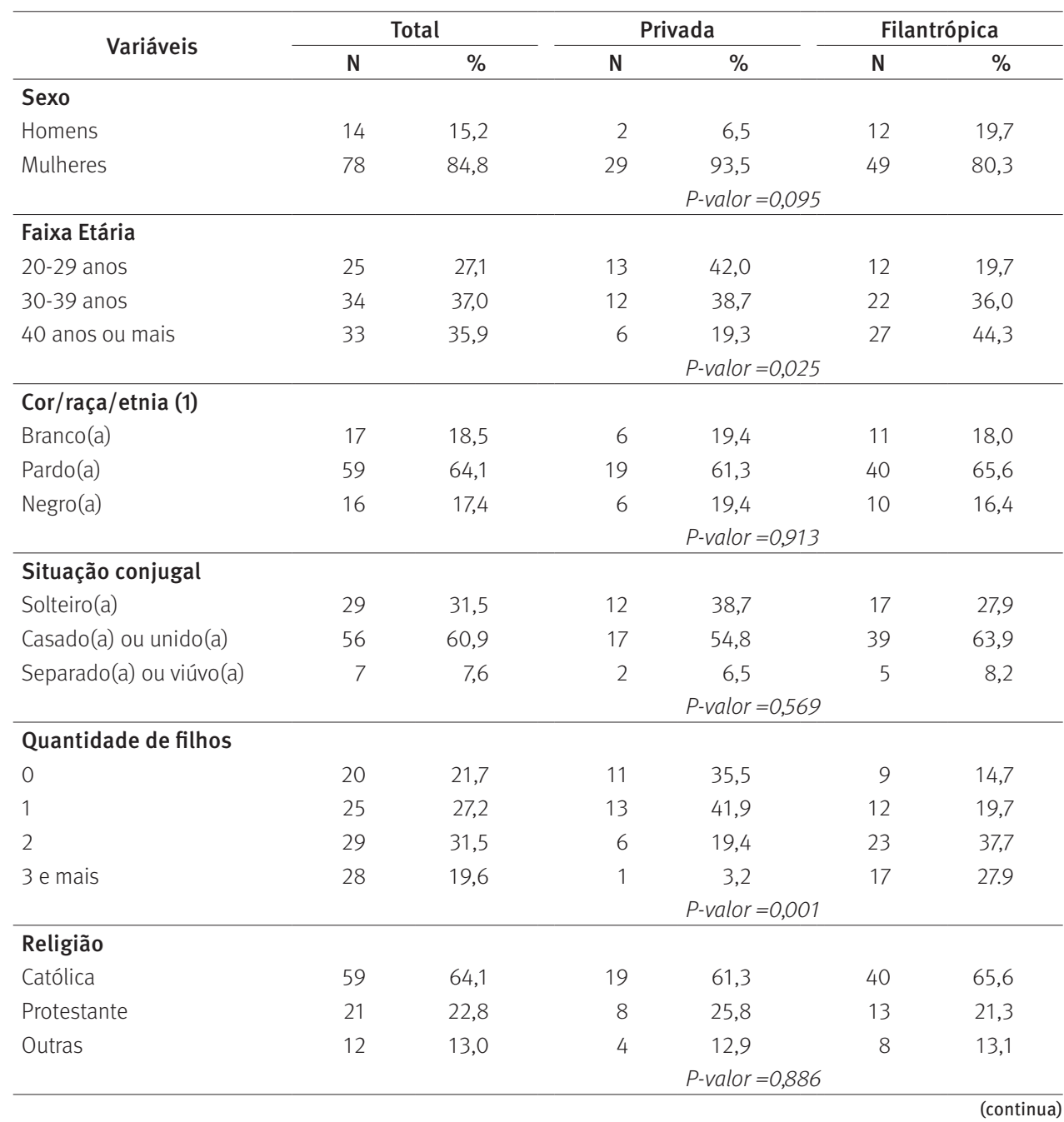


(continuação)

\begin{tabular}{|c|c|c|c|c|c|c|}
\hline \multirow{2}{*}{ Variáveis } & \multicolumn{2}{|c|}{ Total } & \multicolumn{2}{|c|}{ Privada } & \multicolumn{2}{|c|}{ Filantrópica } \\
\hline & $\mathrm{N}$ & $\%$ & $\mathrm{~N}$ & $\%$ & $\mathrm{~N}$ & $\%$ \\
\hline \multicolumn{7}{|l|}{ Nível de escolaridade } \\
\hline $\begin{array}{l}\text { Ensino fundamental } \\
\text { incompleto }\end{array}$ & 18 & 19,6 & 2 & 6,4 & 16 & 26,2 \\
\hline $\begin{array}{l}\text { Fundamental completo/ } \\
\text { médio incompleto }\end{array}$ & 21 & 22,8 & 6 & 19,4 & 15 & 24,6 \\
\hline Médio completo & 49 & 53,3 & 22 & 71,0 & 27 & 44,3 \\
\hline \multirow[t]{2}{*}{$\begin{array}{l}\text { Superior incompleto/ } \\
\text { completo }\end{array}$} & 4 & 4,4 & 1 & 3,2 & 3 & 4,9 \\
\hline & & \multicolumn{5}{|c|}{$P$-valor $=0,065$} \\
\hline \multicolumn{7}{|l|}{ Atualmente estuda? } \\
\hline Sim & 15 & 16,3 & 6 & 19,4 & 9 & 14,8 \\
\hline \multirow[t]{2}{*}{ Não } & 77 & 83,7 & 25 & 80,6 & 52 & 85,2 \\
\hline & & \multicolumn{5}{|c|}{ P-valor $=0,572$} \\
\hline \multicolumn{7}{|l|}{ Renda familiar mensal } \\
\hline De 1 a 3 salários mínimos & 87 & 94,6 & 29 & 93,5 & 58 & 95,1 \\
\hline \multirow[t]{2}{*}{ Mais de 3 salários mínimos } & 5 & 5,4 & 2 & 6,5 & 3 & 4,9 \\
\hline & & \multicolumn{5}{|c|}{ P-valor $=0,065$} \\
\hline
\end{tabular}

Fonte: Pesquisa Cuidadores Formais de Idosos Institucionalizados no Município de Natal/RN, 2012 - UFRN.

(1) Nenhum cuidador formal das ILPI entrevistadas em Natal reportou as categorias indígena e amarela.

Com relação às características ocupacionais, um resultado importante mostrou que a maioria dos cuidadores das ILPI (98\%) possuía carteira de trabalho assinada. Apenas dois entrevistados declararam estar trabalhando temporariamente ou em período de experiência, ambos vinculados a uma ILPI de natureza privada. A Tabela 2 revela as demais características ocupacionais dos cuidadores analisadas nesse artigo. Para $76 \%$ dos entrevistados, o regime de trabalho era de 12 horas diárias com folga de 36 horas ou de 3 ou 4 dias. Esse percentual era mais elevado nas ILPI filantrópicas, nas quais $97 \%$ estavam sob esse regime de trabalho. Nas ILPI privadas, a jornada diária de trabalho era mais baixa: $64 \%$ declararam trabalhar de 6 a 8 horas diárias e apenas 35\%, 12 horas. Em todas as instituições, os cuidadores afirmaram ser responsáveis por uma elevada quantidade de idosos. Todos os entrevistados declararam cuidar diariamente em média de dez ou mais idosos, sendo que para $58,7 \%$ esse número era superior a 20. Nas filantrópicas, esse percentual se eleva para $67,2 \%$ contra $51,9 \%$ nas privadas.

Para analisar a qualificação e a experiência do cuidador, utilizaram-se as informações sobre participação em curso específico para ser cuidador e tempo trabalhando nessa ocupação. Os resultados mostram que $68,5 \%$ fizeram algum curso de capacitação para exercer essa atividade e $50 \%$ possuíam cinco anos ou mais de experiência como cuidador. No entanto, quando a análise é realizada por natureza da ILPI, essa composição diferiu significativamente. Nas instituições filantrópicas, $75,4 \%$ dos cuidadores fizeram curso e $60,7 \%$ declararam exercer essa atividade a mais de cinco anos, enquanto nas privadas esses percentuais se reduzem para $54,8 \%$ e $29 \%$, respectivamente.

Para a maior parte dos cuidadores (84,8\%), essa ocupação era a sua principal fonte de renda, sendo tal proporção ainda maior entre aqueles empregados nas ILPI filantrópicas 
Barbosa, L.M. et al. Qualidade de vida relacionada à saúde dos cuidadores formais de idosos institucionalizados...

(90,2\%). Entre os cuidadores das instituições privadas, essa parcela correspondia a 74,2\%. Além de esse trabalho ser a principal fonte de renda para a maioria dos entrevistados, os resultados apontam que o nível de satisfação com a ocupação exercida era elevado: em torno de $92 \%$ declararam estarem muito satisfeitos ou satisfeitos em serem cuidadores de idosos. Mas é importante ressaltar que quase $20 \%$ dos cuidadores pensaram em abandonar essa atividade. A análise por natureza das instituições não apresentou diferenças estatisticamente significativas.

TABELA 2

Cuidadores formais de idosos das ILPI, por natureza da instituição, segundo variáveis ocupacionais Município de Natal - 2012

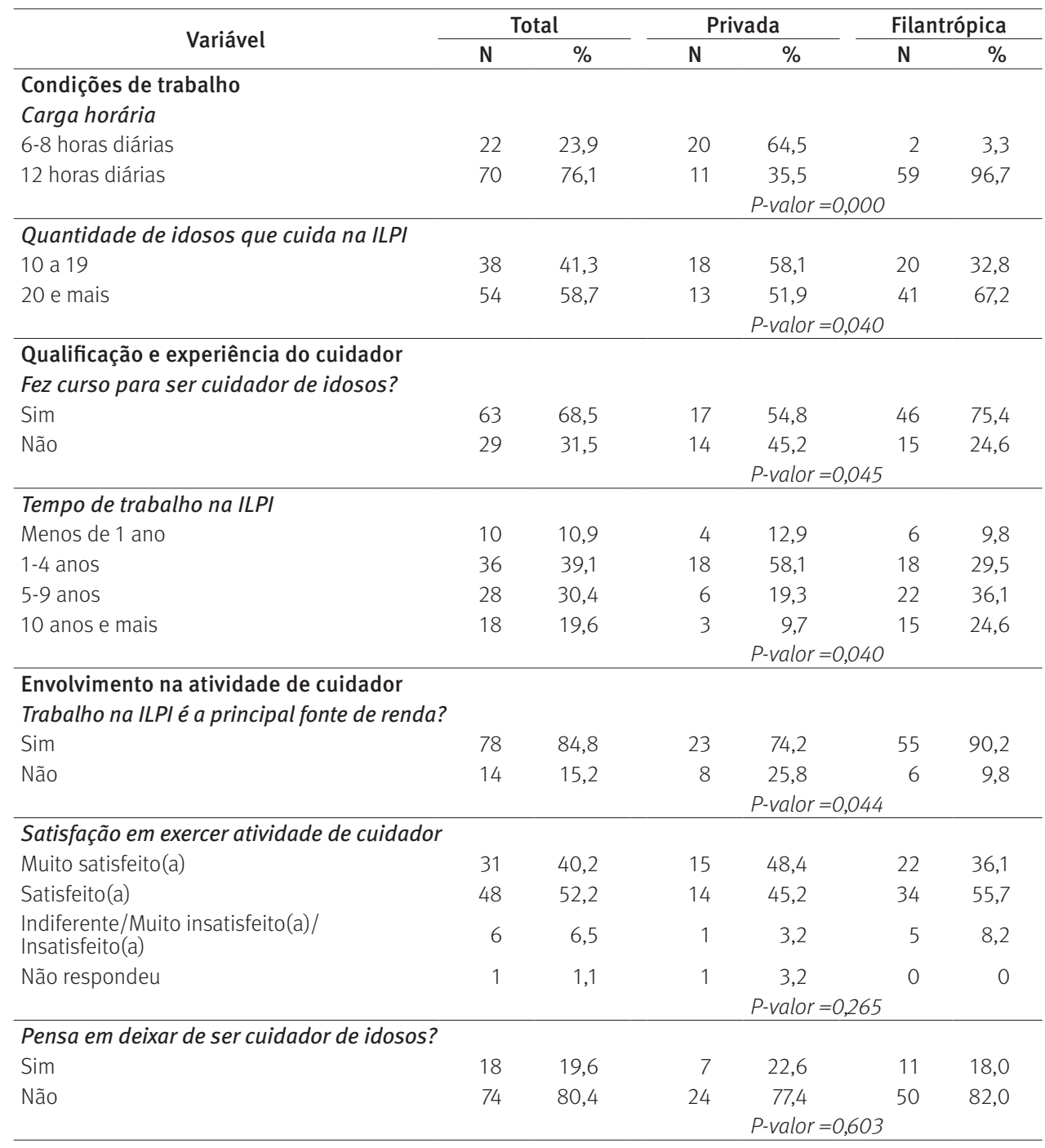

Fonte: Pesquisa Cuidadores Formais de Idosos Institucionalizados no Município de Natal/RN, 2012 - UFRN. 
Barbosa, L.M. et al. Qualidade de vida relacionada à saúde dos cuidadores formais de idosos institucionalizados...

No que se refere à saúde dos cuidadores, a maioria avaliou sua saúde como excelente, muito boa e boa (90,2\%), não havendo diferenças significativas por natureza da instituição. As diferenças foram significativas na comparação do estado de saúde geral com aquele do ano anterior à pesquisa. Entre os cuidadores das ILPI filantrópicas, observou-se um percentual relativamente elevado de profissionais que reportaram ter sofrido uma perda de saúde no período: $23 \%$ contra $6,5 \%$ dos cuidadores em ILPI privadas (Tabela 3 ).

TABELA 3

Cuidadores formais de idosos das ILPI, por natureza da instituição, segundo avaliação do estado de saúde geral

Município de Natal - 2012

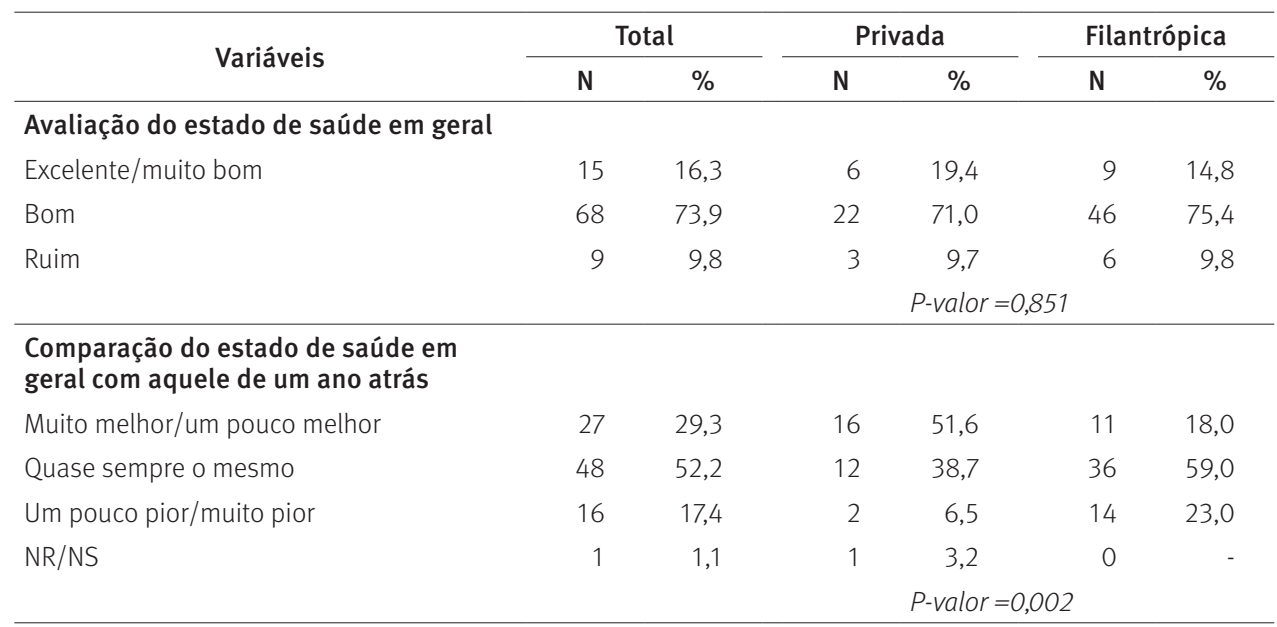

Fonte: Pesquisa Cuidadores Formais de Idosos Institucionalizados no Município de Natal/RN, 2012 - UFRN.

A Tabela 4 apresenta a média dos valores dos domínios definidos pelo SF-36 para mensurar a qualidade de vida relacionada à saúde dos cuidadores de idosos institucionalizados. De acordo com os resultados encontrados, o valor médio dos índices variou de 87,1 a 54,2. A maior perda de saúde foi relacionada ao domínio do estado geral de saúde, cuja média correspondia a 54,2, seguido pelos domínios de vitalidade $(60,9)$, dor $(67,8)$ e saúde mental $(78,8)$. 0 domínio referente à capacidade funcional apresentou a menor perda (com média de 87,1). A análise por natureza da ILPI não mostrou diferenças significativas na saúde dos cuidadores mensurada por esses domínios.

Quando a análise é realizada por tempo dedicado ao trabalho como cuidador, também não foram encontradas diferenças significativas entre os dois grupos para quase todos os domínios de saúde do SF-36 (Tabela 5). Apenas para o domínio relacionado ao estado geral de saúde, verificou-se uma maior deterioração para aqueles que estão nessa ocupação há cinco anos ou mais, com valor médio do índice igual a 51,1 contra 57,7 para os que têm menos de cinco anos nessa profissão. Para os que exerciam a ocupação há dez anos ou mais, constatou-se diferença significativa no domínio da capacidade funcional: 79,7 contra 88,6 para aqueles que estavam nessa atividade há menos dez anos (Tabela 5). 
Barbosa, L.M. et al. Qualidade de vida relacionada à saúde dos cuidadores formais de idosos institucionalizados...

TABELA 4

Valores dos domínios avaliados pelo SF-36 dos cuidadores formais de idosos das ILPI, por natureza da instituição

Município de Natal - 2012

\begin{tabular}{|c|c|c|c|c|c|c|}
\hline \multirow{2}{*}{ Domínio } & \multicolumn{3}{|c|}{ Média } & \multicolumn{3}{|c|}{ Desvio padrão } \\
\hline & Total & Filantrópica & Privada & Total & Filantrópica & Privada \\
\hline \multirow[t]{2}{*}{ Domínio 1: Capacidade funcional } & 87,1 & 87,5 & 86,3 & 17,1 & 18,8 & 13,5 \\
\hline & & \multicolumn{2}{|c|}{ P-valor $=0,314$} & & & \\
\hline \multirow[t]{2}{*}{ Domínio 2: Aspectos físicos } & 86,9 & 88,1 & 84,7 & 25,0 & 25,3 & 24,7 \\
\hline & \multicolumn{6}{|c|}{$P$-valor $=0,353$} \\
\hline \multirow[t]{2}{*}{ Domínio 3: Dor } & 67,8 & 68,2 & 67,1 & 24,3 & 24,6 & 24,2 \\
\hline & & P-valor & $=0,671$ & & & \\
\hline \multirow[t]{2}{*}{ Domínio 4: Estado geral de saúde } & 54,2 & 52,0 & 58,5 & 15,8 & 16,0 & 14,6 \\
\hline & & P-valo & $=0,113$ & & & \\
\hline \multirow[t]{2}{*}{ Domínio 5: Vitalidade } & 60,9 & 61,3 & 60,2 & 11,6 & 12,2 & 10,4 \\
\hline & & P-valor & $=0,480$ & & & \\
\hline \multirow[t]{2}{*}{ Domínio 6: Aspectos sociais } & 84,8 & 85,9 & 82,7 & 20,5 & 21,7 & 18,2 \\
\hline & & P-valo & $=0,119$ & & & \\
\hline \multirow[t]{2}{*}{ Domínio 7: Aspectos emocionais } & 83,0 & 85,2 & 78,5 & 31,8 & 28,9 & 37,1 \\
\hline & & P-valor & $=0,566$ & & & \\
\hline \multirow[t]{2}{*}{ Domínio 8: Saúde mental } & 78,8 & 79,0 & 78,6 & 18,63 & 19,2 & 17,9 \\
\hline & & P-valor & $=0,779$ & & & \\
\hline
\end{tabular}

Fonte: Pesquisa Cuidadores Formais de Idosos Institucionalizados no Município de Natal/RN, 2012 - UFRN.

TABELA 5

Valores dos domínios avaliados pelo SF-36 dos cuidadores formais de idosos das ILPI, por tempo na ocupação

Município de Natal - 2012

\begin{tabular}{|c|c|c|c|c|}
\hline \multirow[b]{2}{*}{ Domínios } & \multicolumn{4}{|c|}{ Tempo na ocupação } \\
\hline & $\begin{array}{c}\text { Menos de } 5 \text { anos } \\
n=46\end{array}$ & $\begin{array}{c}5 \text { anos e mais } \\
n=46\end{array}$ & $\begin{array}{c}\text { Menos de } 10 \text { anos } \\
n=76\end{array}$ & $\begin{array}{c}10 \text { anos e mais } \\
n=16\end{array}$ \\
\hline \multirow[t]{2}{*}{ Domínio 1: Capacidade funcional } & 87,2 & 87,0 & 88,6 & 79,7 \\
\hline & \multicolumn{2}{|c|}{$p$-value $=0,561$} & \multicolumn{2}{|c|}{$p$-value $=0,057$} \\
\hline \multirow[t]{2}{*}{ Domínio 2: Aspectos físicos } & 87,5 & 86,4 & 88,2 & 81,2 \\
\hline & \multicolumn{2}{|c|}{$p$-value $=0,682$} & \multicolumn{2}{|c|}{$p$-value $=0,317$} \\
\hline \multirow[t]{2}{*}{ Domínio 3: Dor } & 69,3 & 66,4 & 68,6 & 64,4 \\
\hline & \multicolumn{2}{|c|}{$p$-value $=0,349$} & \multicolumn{2}{|c|}{$p$-value $=0,532$} \\
\hline \multirow[t]{2}{*}{ Domínio 4: Estado geral de saúde } & 57,3 & 51,1 & 54,6 & 52,1 \\
\hline & \multicolumn{2}{|c|}{$p$-value $=0,055$} & \multicolumn{2}{|c|}{$p$-value $=0,564$} \\
\hline \multirow[t]{2}{*}{ Domínio 5: Vitalidade } & 60,8 & 61,1 & 60,3 & 63,8 \\
\hline & \multicolumn{2}{|c|}{$p$-value $=0,810$} & \multicolumn{2}{|c|}{$p$-value $=0,286$} \\
\hline \multirow[t]{2}{*}{ Domínio 6: Aspectos sociais } & 80,7 & 88,9 & 84,5 & 85,9 \\
\hline & \multicolumn{2}{|c|}{$p$-value $=0,178$} & \multicolumn{2}{|c|}{$p$-value $=0,806$} \\
\hline \multirow[t]{2}{*}{ Domínio 7: Aspectos emocionais } & 81,2 & 84,8 & 82,9 & 83,3 \\
\hline & \multicolumn{2}{|c|}{$p$-value $=0,413$} & \multicolumn{2}{|c|}{$p$-value $=0,960$} \\
\hline \multirow[t]{2}{*}{ Domínio 8: Saúde mental } & 80,3 & 77,3 & 78,3 & 81,5 \\
\hline & \multicolumn{2}{|c|}{$p$-value $=0,357$} & \multicolumn{2}{|c|}{$p$-value $=0,530$} \\
\hline
\end{tabular}

Fonte: Pesquisa Cuidadores Formais de Idosos Institucionalizados no Município de Natal/RN, 2012 - UFRN.

Esse resultado pode, em certa medida, captar os problemas de saúde relacionados tanto às características desta ocupação como à idade dos cuidadores. Como esperado, a idade média dos cuidadores com maior tempo de atuação foi significativamente maior do 
Barbosa, L.M. et al. Qualidade de vida relacionada à saúde dos cuidadores formais de idosos institucionalizados...

que a daqueles que estão desempenhando essa função há menos tempo: 41 anos de idade (cinco anos ou mais de atuação) e 45 (dez anos ou mais de atuação), contra 33 anos de idade (menos de cinco anos de atuação) e 36 (menos de dez anos de atuação). Analisando a média dos valores em cada domínio por grupo etário, observou-se uma diferença significativa apenas no domínio 1 (capacidade funcional), cuja média foi de 88,2, para os indivíduos com idade de 20 a 49 anos, e 76,7 para aqueles com 50 anos e mais ( $p$-value $=0,055$ ).

\section{Discussão}

Esse artigo teve como objetivo caracterizar o perfil dos cuidadores formais dos idosos institucionalizados em Natal-RN, segundo natureza da ILPI (filantrópica e privada). A análise abordou principalmente a qualidade de vida relacionada à saúde. 0 estudo utilizou informações provenientes de uma pesquisa de campo realizada em 2012, que possibilitou a construção de uma base de dados inédita em um município brasileiro. Nesse estudo, foram investigadas 11 das 14 ILPI que tinham certificado de inscrição emitido pelo Conselho Municipal do Idoso em Natal-RN, contemplando $76 \%$ do total de cuidadores formais empregados nessas 11 instituições no momento da pesquisa.

A maior parte dos cuidadores entrevistados era composta por mulheres (85\%), resultado esperado e já encontrado em outros estudos que analisaram o perfil do cuidador formal (RIBEIRO et al., 2008; LOPES et al., 2012; KAWASAKI; DIOGO, 2001a; SILVA et al., 2016) e informal (NAKATANI et al., 2003; OLIVEIRA et al., 2006; LOUREIRO et al., 2013; FERREIRA et al., 2011) no Brasil e em diferentes sociedades (CHAN et al., 2013; ARAl et al., 2014). Tradicionalmente, a atividade associada ao cuidado é exercida primordialmente pelas mulheres. Apesar dos avanços observados no mercado de trabalho brasileiro, ainda permanece 0 entendimento de que a mulher é a principal responsável pelas tarefas associadas ao trabalho doméstico e reprodutivo, o que inclui o ato de cuidar. Historicamente, essa atribuição refletiria uma visão de que essa atividade seria uma habilidade inerente às mulheres em decorrência da maternidade (VASCONCELOS, 2009; FERREIRA et al., 2011; KUCHEMANN, 2012).

Em relação à estrutura etária, observou-se que a maior parte dos cuidadores possuía mais de 30 anos de idade (73\%), com média e mediana igual a 37 e 36, respectivamente. Esse resultado é maior do que a média de 33 anos encontrada por Araújo et al. (2014), que avaliaram o perfil de 32 cuidadores formais em uma ILPI no Vale do Paraíba em 2011, e menor do que aquela obtida por Medeiros (2014), que analisou o perfil de 18 cuidadores formais em uma ILPI em João Pessoa, Paraíba. Quanto à situação conjugal, 61\% dos cuidadores em Natal declararam ser casados ou unidos. Esse percentual é elevado em relação tanto à população acima de dez anos no município (47\%) (IBGE, 2010) como ao resultado encontrado em outros estudos tais como Medeiros (2014) e Ribeiro et al. (2008), cuja proporção de cuidadores nesse estado civil correspondia a, respectivamente, $50 \%$ e $44 \%$.

A condição socioeconômica revela uma situação menos privilegiada dos cuidadores em relação à população total de Natal. De acordo com os resultados encontrados, $95 \%$ dos 
Barbosa, L.M. et al. Qualidade de vida relacionada à saúde dos cuidadores formais de idosos institucionalizados...

cuidadores das ILPI natalenses possuíam renda familiar mensal de 1 a 3 salários mínimos. Na população do município, $78 \%$ dos indivíduos com mais de dez anos de idade ocupados na semana de referência do Censo Demográfico 2010 recebiam até três salários mínimos (IBGE 2010). Contudo, o rendimento dos cuidadores formais em Natal encontrava-se no mesmo patamar daquele observado em ILPI de Belo Horizonte em 2008. Segundo Ribeiro et al. (2008), 82,2\% dos cuidadores formais em instituições desse município recebiam até dois salários mínimos mensais.

Em relação ao total da população de Natal, observou-se que os cuidadores formais das ILPI apresentavam um nível educacional relativamente mais elevado. Enquanto no município $45 \%$ dos indivíduos com mais de 24 anos de idade tinham ensino médio completo ou mais (IBGE 2010), entre os cuidadores formais esse percentual era de $58 \%$. Além disso, a proporção dos cuidadores que possuíam menos que o ensino fundamental completo (19,6\%) era inferior aos 40\% observados na população geral acima de 24 anos (IBGE 2010). ${ }^{1}$ Devido à característica dessa ocupação, foram encontrados apenas dois cuidadores que declararam possuir ensino superior completo. 0 percentual de cuidadores formais com ensino médio em Natal foi ligeiramente maior do que os $50 \%$ obtidos por Medeiros (2014), mas inferior aos $75 \%$ encontrados por Couto (2012), que analisou as características de 14 cuidadores formais domiciliares por meio de um estudo qualitativo em 2011, no município de São Paulo.

Outra característica importante que reflete a qualificação desse profissional é a realização de curso específico para cuidador de idosos, que alcançou 68,5\% dos cuidadores entrevistados em Natal. Esse resultado é similar ao encontrado por Silva et al. (2016), que também analisaram os cuidadores de idosos institucionalizados em Natal, e menor ao observado por Camarano (2008b), que investigou as ILPI no Rio Grande do Norte. De acordo com Camarano (2008b), 98 (86\%) dos 114 cuidadores empregados nas 29 ILPI identificadas no estado receberam algum tipo de capacitação. Como a profissão ainda não está regulamentada, os cursos de cuidadores de idosos, além de não serem uma exigência para a prática do cuidado formal, não possuem um formato homogeneizado quanto ao seu escopo, conteúdo e carga horária. No entanto, apesar da não obrigatoriedade, devido à concorrência, o mercado em certa medida faz com que haja uma procura por um mínimo de formação básica para exercer essas atividades (RIBEIRO, 2015; GROISMAN, 2013). 0 $\mathrm{PL} 4702 / 2012$, caso seja aprovado, prevê que os cuidadores tenham pelo menos o ensino fundamental completo e conclusão do curso de formação de cuidador de idosos (RIBEIRO, 2015; DUARTE et al., 2016). Essas exigências estariam sendo parcialmente atendidas nas ILPI do município de Natal, mas é importante ressaltar que 19,6\% dos cuidadores não possuíam ensino fundamental completo e $31,5 \%$ não realizaram o curso de formação de cuidador de idosos, indicando que ainda há espaço para a formulação de políticas que incentivem a qualificação desses profissionais.

\footnotetext{
${ }^{1}$ Para o cálculo da proporção de indivíduos por grupo de escolaridade na população geral, consideraram-se as pessoas de referência na família e o respectivo cônjuge ou companheiro, ambos com idade igual ou superior a 24 anos.
} 
A comparação entre as ILPI filantrópicas e privadas mostra diferenças significativas em relação ao nível de escolaridade e à realização de cursos específicos para o cuidado dos idosos. Nas instituições privadas, o nível educacional era mais elevado, com $71 \%$ dos cuidadores possuindo ensino médio completo e apenas 6,4\% com nível fundamental incompleto, enquanto nas filantrópicas esses percentuais correspondiam a 44,3\% e 26,2\%, respectivamente. Por outro lado, a proporção daqueles que declararam ter feito o curso de cuidador de idosos era mais elevada nas filantrópicas: $75 \%$ contra $54,8 \%$ nas privadas. Esse resultado reflete, em certa medida, a baixa qualificação dos cuidadores das ILPI filantrópicas. Por ter menor nível de instrução, é provável que a realização de cursos de cuidador seja mais demandada para compensar a baixa qualificação formal desses profissionais.

Com relação ao tempo de experiência, os resultados da pesquisa mostram que $50 \%$ estavam há cinco anos ou mais exercendo suas atividades como cuidador. Esse resultado é igual ao encontrado por Medeiros (2014) e maior do que os $40 \%$ observados por Ribeiro et al. (2008). Considerando a natureza da ILPI, foram verificadas diferenças significativas, de forma que os profissionais que atuavam nas privadas tinham menor experiência. Em torno de $61 \%$ dos cuidadores empregados nas ILPI filantrópicas reportaram ter cinco anos ou mais de experiência contra $29 \%$ nas privadas. Diferença similar no tempo de experiência como cuidador foi obtido por Ribeiro et al. (2008). Esse resultado pode estar associado à diferença tanto no tempo de funcionamento das ILPI como no perfil etário dos cuidadores de Natal segundo a natureza das instituições. As ILPI filantrópicas apresentaram cuidadores com idades mais elevadas do que as privadas, além de serem instituições mais antigas no município. As ILPIs de natureza privada foram criadas mais recentemente e revelaram uma média de 5,7 anos de funcionamento, enquanto as entidades filantrópicas apresentaram uma média bem mais elevada, em torno de 33 anos de funcionamento. Até o ano da realização da pesquisa (2012), as duas ILPIs mais antigas em Natal tinham 12 anos (de natureza privada) e 68 anos (de natureza filantrópica) de funcionamento.

Analisando as características ocupacionais, $76 \%$ do total de cuidadores revelaram trabalhar em um regime de 12 horas diárias com folga de 36 horas ou de 3 ou 4 dias. Nas filantrópicas, esse percentual aumenta para 97\%, em contraposição aos 35\% nas instituições privadas. Nestas últimas, a maior parte dos cuidadores (64\%) declarou trabalhar de 6 a 8 horas diárias. Associado a essa jornada de trabalho, observou-se que cada cuidador era responsável por um número médio elevado de idosos. Em torno de 59\% dos cuidadores afirmaram cuidar de 20 idosos e mais, sendo que nas filantrópicas esse percentual ascende para $67 \%$, contra $52 \%$ nas privadas. Esses resultados apontam para a realização de atividades laborais mais exaustivas, principalmente, entre aqueles que atuam nas ILPI filantrópicas. Considerando-se o tipo de trabalho exercido, esse quadro evidencia ainda mais a sobrecarga de trabalho dos cuidadores. De acordo com Barbosa (2013), em Natal, havia 388 idosos residentes nessas instituições. Desses, 321 (83\%) não conseguiram realizar ou foram reprovados no teste do Minimental, ou seja, apresentaram capacidade cognitiva comprometida, requerendo assim monitoramento constante. Dentre os 67 idosos 
Barbosa, L.M. et al. Qualidade de vida relacionada à saúde dos cuidadores formais de idosos institucionalizados...

aprovados no teste, $42 \%$ tinham dificuldades na realização das atividades básicas da vida diária (ABVD). 0 estudo ainda mostra que $90 \%$ dos idosos institucionalizados apresentavam dependência moderada ou severa. Esse resultado representa de forma geral o perfil observado no Brasil. Duarte et al. (2016) salientam que nas ILPI brasileiras, sobretudo filantrópicas, as condições de saúde dos idosos são bastante debilitadas, demandando cuidados médicos especializados. De acordo com os autores, essa situação contraria as diretrizes preconizadas pela Política Nacional do Idoso (PNI), que proíbe a residência de idosos em ILPI com necessidade de assistência médica permanente. Diante desse quadro, percebe-se uma sobrecarga física e emocional dos cuidadores devido às condições de saúde seriamente debilitadas dos idosos que estão sob os seus cuidados. Para proteger o profissional desse desgaste, a regulamentação da Anvisa preconiza que cada cuidador se responsabilize em média por 8 a 10 idosos nessas condições de saúde. Entretanto, o valor médio encontrado nas ILPI tanto privadas como filantrópicas em Natal ficou bem acima do recomendado (ANVISA, 2005).

0 tipo de trabalho exercido pelo profissional que atua nas ILPI, aliado à sobrecarga exaustiva devido ao elevado número de idosos que cada cuidador declara ser responsável em Natal, pode acarretar perdas de saúde e, em última instância, afetar a qualidade do serviço prestado. Dessa forma, é importante avaliar a qualidade de vida relacionada à saúde dos cuidadores. No presente estudo, essa temática foi abordada por meio do instrumento SF-36. Os resultados mostram que a maior parte dos cuidadores avaliou seu estado de saúde como muito bom e bom e apenas $9 \%$ declararam ter saúde ruim. No que se refere à comparação do estado de saúde atual com aquele do ano anterior à data da pesquisa, os dados revelaram que $17 \%$ declararam ter sofrido uma piora nesse período. Esse percentual difere segundo a natureza da ILPI: $23 \%$ nas filantrópicas contra 6,5\% nas privadas. Essa diferença pode refletir tanto um efeito de composição (estrutura etária menos envelhecida dos cuidadores das ILPI privadas) como um efeito associado às condições de trabalho (maior jornada de trabalho e maior número de idosos por cuidador nas instituições filantrópicas).

Analisando os escores médios do SF-36, os resultados dependem do domínio considerado. A maior perda de saúde foi observada para o domínio estado de saúde geral (escore médio igual a 54,2), seguido pelos domínios vitalidade $(60,9)$ e dor $(67,8)$. No caso do domínio do estado de saúde geral, a perda foi bastante expressiva, apresentando escore médio similar ao encontrado por Morales et al. (2007) para pacientes com esclerose múltipla $(56,3)$. Os escores médios relativos aos domínios vitalidade e dor foram levemente superiores aos observados para cuidadores informais de pacientes com Alzheimer: 56,8 e 63,3, respectivamente (PINTO et al., 2009). Comparando com os escores médios estimados para a população geral brasileira, que, segundo Pinto et al. (2009), eram de 75 para estado de saúde geral, 70 para vitalidade e 73 para dor, a perda de saúde dos cuidadores das ILPI em Natal seria superior em 28\%, 13\% e 7\% para esses domínios, respectivamente.

A perda de saúde dos cuidadores das ILPI de Natal foi menor nos domínios de capacidade funcional e aspectos físicos, com escores médios de 87,1 e 86,9, respectivamente. 
Barbosa, L.M. et al. Qualidade de vida relacionada à saúde dos cuidadores formais de idosos institucionalizados...

Esses valores eram maiores ou se encontravam nos mesmos patamares daqueles estimados para a população brasileira, que correspondiam a 83 (capacidade funcional) e 87 (aspectos físicos) (PINTO et al., 2009). Os resultados obtidos para esses dois domínios entre os cuidadores das ILPI em Natal são melhores do que os encontrados na literatura para cuidadores informais. No caso de capacidade funcional, o escore médio era de 83 para os cuidadores informais de pacientes com problemas neurológicos e com Alzheimer (NICKEL et al., 2010; PINTO et al., 2009). Para o domínio aspectos físicos, os escores médios eram de 71 e 58, respectivamente, para os dois tipos de cuidadores informais (NICKEL et al., 2010; PINTO et al., 2009). Quando se considera o tempo dedicado ao trabalho como cuidador, constatou-se uma perda mais acentuada no domínio da capacidade funcional entre os cuidadores das ILPI de Natal que exerciam essa atividade há mais de dez anos, cujo escore médio cai para 79,7, valor inferior ao encontrado para os cuidadores informais dos pacientes com problemas neurológicos ou com Alzheimer.

Outro resultado que chama a atenção é aquele observado para as dimensões associadas aos aspectos emocionais e saúde mental. Nos dois casos, os escores médios encontrados foram similares aos estimados para a população brasileira: 83 e 79 para cuidadores das ILPI em Natal e 86 e 73 para a população geral, respectivamente (PINTO et al., 2009). Esse resultado surpreende tendo em vista evidências já encontradas na literatura acerca da perda de saúde nesses dois domínios entre cuidadores de idosos (ARAl et al., 2014; CHAN et al., 2013; PINTO et al., 2009). Comparando os resultados desse estudo com os realizados para os cuidadores domiciliares, percebe-se uma clara diferença em prol dos profissionais empregados nas instituições em Natal. Os escores médios dos domínios referentes aos aspectos emocionais e saúde mental correspondiam a, respectivamente, 50,9 e 60,9 para cuidadores de idosos domiciliares no município de São Paulo (FERREIRA et al., 2011) e 72,5 e 71,1 para cuidadores informais de pacientes com problemas neurológicos (NICKEL et al., 2010).

Como observado, a menor perda de saúde percebida entre cuidadores formais das ILPI de Natal referia-se aos domínios capacidade funcional, aspectos físicos, aspectos emocionais e saúde mental, fato que pode, em certa medida, refletir um efeito de seleção. Esses profissionais, enquanto permanecem exercendo a atividade laboral, tendem a apresentar uma condição física melhor para conseguir desempenhar suas funções nas ILPI em que estão empregados. No caso dos cuidadores informais, como muitas vezes o cuidado é prestado por um familiar, mesmo estando com a saúde mais debilitada, a ausência de uma alternativa de cuidado obriga esses indivíduos a ofertarem tais serviços. Além disso, o cuidado de um parente implica uma perda emocional mais grave, tendo em vista o grau de envolvimento com o idoso que está recebendo os cuidados. Ressalta-se ainda que, nesse estudo, dentre os cuidadores empregados nas ILPI, $24 \%$ não foram entrevistados pois estavam em férias ou em licença de qualquer natureza, inclusive médica. 0 fato de terem sido excluídos cuidadores em licença médica pode também estar contribuindo para esse viés de seleção. 
Um avanço desse estudo seria analisar o perfil de indivíduos que foram cuidadores formais de ILPI e que, no presente, não exercem mais essas atividades. Como visto, o tempo dedicado a essa atividade parece comprometer a saúde desses profissionais, especialmente no que se refere à capacidade funcional. Dessa forma, a análise das condições de saúde dos indivíduos que não exercem mais esse ofício pode auxiliar no entendimento do peso dessas atividades sobre a qualidade de vida relacionada à saúde. Dado que já exerceram essa atividade específica, seria possível verificar em que medida o envolvimento com as execuções das tarefas no cuidar de um idoso pode impactar em perdas de saúde futura.

Este trabalho deve servir de base para identificar as limitações no exercício desta atividade de cuidador formal de ILPI e orientar a elaboração de políticas públicas voltadas para a melhoria da qualidade de vida do cuidador formal e, consequentemente, do idoso. Os resultados desse estudo também apontam para um nicho de mercado de trabalho recente e crescente, devido ao aumento da proporção de idosos no Brasil, permitindo dimensionar qual é o perfil do público-alvo que os cursos de capacitação de cuidadores de idosos podem atingir, de forma a proporcionar uma melhor eficiência no serviço desses profissionais, além de uma adaptação dos idosos nas ILPI. Nesse cenário, sugerem-se mais estudos que insiram, na temática do envelhecimento populacional, os atores presentes no processo - 0 idoso, o cuidador formal e a família do idoso -, sob a ótica da institucionalização, de forma a subsidiar corretamente as políticas públicas assistencialistas que visam o bem-estar e uma melhor qualidade de vida para a população.

Adicionalmente, é importante se pensar nos custos envolvidos para o provimento desses cuidados. De acordo com estimações realizadas por Rocha (2015) para o Brasil, a ausência de uma cobertura pública ou privada de serviços de longa permanência para idosos pode acarretar em custos privados elevados, implicando mais um ônus para os idosos e seus familiares. Esse cenário é especialmente verdadeiro entre os idosos mais vulneráveis com elevado grau de dependência e que possuem recursos escassos para arcar com os custos envolvidos nesses cuidados. Alguns modelos de oferta e financiamento de cuidados de longa permanência são adotados em países desenvolvidos que apresentam um processo mais avançado de envelhecimento populacional. Um exemplo seria o modelo de seguro social adotado no Japão, Inglaterra, Países Baixos, Suíça, e Alemanha, que permite suavizar para as famílias o peso financeiro desses serviços (ROCHA, 2015). A análise da experiência internacional pode servir como um balizador para a construção de um modelo de financiamento e provimento do cuidado de longa permanência no Brasil, no sentido de desonerar as famílias do ponto de vista tanto financeiro como da qualidade de vida relacionada à saúde.

\section{Conclusão}

0 presente estudo contribuiu para identificar o perfil do cuidador formal nas ILPI no município de Natal, ressaltando o peso dessa ocupação na qualidade de vida relacionada 
à saúde. Os resultados mostram que a maior perda de saúde refere-se aos domínios estado de saúde geral, vitalidade e dor, refletindo, em certa medida, a sobrecarga de trabalho desses cuidadores. Como foi verificado, tanto a jornada de trabalho como o total de idosos sob a responsabilidade de cada cuidador são bastante elevadas, sendo inclusive superiores ao previsto pela regulação da Anvisa. Esse quadro se torna mais preocupante quando se analisam as condições de saúde dos idosos institucionalizados, em que a maior parte apresenta grau de dependência elevada, o que demanda maior esforço físico no cuidado prestado. Contudo, é importante ressaltar que a perda de saúde dos cuidadores formais, principalmente, nos domínios saúde mental e capacidade física é baixa quando comparados aos cuidadores informais. Com o declínio da fecundidade, haverá cada vez menos oferta de familiares para o apoio e cuidado do idoso, o que poderá pressionar ainda mais, emocional e fisicamente, os cuidadores informais disponíveis para exercerem essas funções. Esses resultados, portanto, sinalizam a importância de se promoverem políticas para a construção de uma rede formalizada de apoio ao idoso.

\section{Referências}

ADORNO, M. L. G. R.; BRASIL-NETO, J. P. Assessment of quality of life by the SF-36 questionnaire in chronic low back pain cases. Acta Ortopédica Brasileira, São Paulo, v. 21, n. 4, p. 202-207, 2013.

ALVES, J. E. D. A transição demográfica e a janela de oportunidades. São Paulo: Instituto Fernand Braudel de Economia Mundial, 2008.

ALVES-SILVA, J. D.; SCORSOLINI-COMIN, F.; SANTOS, M. A. Idosos em instituições de longa permanência: desenvolvimento, condições de vida e saúde. Psicologia: Reflexão e Crítica, Porto Alegre, v. 26, n. 4, p. 820-830, dez. 2013.

ANVISA - Agência Nacional de Vigilância Sanitária. Resolução RDC no 283, de 26 de setembro de 2005. Aprova o Regulamento Técnico que define normas de funcionamento para as Instituições de Longa Permanência para Idosos. Brasília: Anvisa, 2005.

ARAÚJO, C. L. O.; LOPES, C. M.; SANTOS, G. R.; JUNQUEIRA, L. P. Perfil dos colaboradores de uma instituição de longa permanência para idosos (ILPI). Revista Kairós Gerontologia, v. 17, n. 1, p. 219-230, 2014.

ARAI, Y.; KUMAMOTO, K.; MIZUNO, Y.; WASHIO, M. Depression among family caregivers of community-dwelling older people who used services under the Long Term Care Insurance program: a large-scale population-based study in Japan. Aging Ment Health, v. 18, n. 1, p. 81-91, 2014.

BARBOSA, M. F. M. Envelhecimento populacional: um diagnóstico dos idosos institucionalizados, em Natal/RN. 2013. 142 f. Dissertação (Mestrado) - Universidade Federal do Rio Grande do Norte, Centro de Ciências Exatas e da Terra, Programa de Pós-Graduação em Demografia, Natal, RN, 2013.

BARTOLO, M.; DE LUCA, D.; SERRAO, M.; SINFORIANI, E.; ZUCCHELLA, C.; SANDRINI, G. Caregivers burden and needs in community neuro rehabilitation. Journal Rehabilitation Medicine, v. 42, n. 9, p. 818-822, 2010.

BATISTA, A. S.; JACCOUD, L. B.; AQUINO, L.; EL-MOOR, P. D. Envelhecimento e dependência: desafios para a organização da proteção social. Brasília: Ministério da Previdência Social, 2008 (Coleção Previdência Social, v. 28). 
Barbosa, L.M. et al. Qualidade de vida relacionada à saúde dos cuidadores formais de idosos institucionalizados...

BRITO, F. A transição demográfica no contexto internacional. Belo Horizonte: Cedeplar/UFMG, 2007 (Texto para discussão, n. 317).

CAMARANO, A. A. Cuidados de longa duração para a população idosa: família ou instituição de longa permanência? Sinais Sociais, v. 7, n. 3, p. 10-39, 2008a.

Características das instituições de longa permanência para idosos - região Nordeste. Brasília: Ipea; Presidência da República, 2008b.

CAMARANO, A. A.; PASSINATO, M. T. O envelhecimento populacional na agenda das políticas públicas. In: CAMARANO, A. A. (Org.). Muito além dos 60: os novos idosos brasileiros. Rio de Janeiro: Ipea, 2004. p. 253-292.

CAMARANO, A.A .; KANSO, S.; MELLO, J. L. Como vive o idoso brasileiro? In: CAMARANO, A. A. (Org.). Muito além dos 60: os novos idosos brasileiros. Rio de Janeiro: Ipea, 2004a. p. 25-73.

CAMARANO, A. A.; KANSO, S.; MELLO, J. L.; PASINATO, M. T. Famílias: espaço de compartilhamento de recursos e vulnerabilidades. In: CAMARANO, A. A. (Org.). Muito além dos 60: os novos idosos brasileiros. Rio de Janeiro: Ipea, 2004b. p.137-168.

CAMARANO, A. A.; MELLO, J. L. Cuidados de longa duração no Brasil: o arcabouço legal e as ações governamentais. In: CAMARANO, A. A. (Org.). Cuidados de longa duração para a população idosa: um novo risco social a ser assumido? Rio de Janeiro: Ipea, 2010. p. 68-92.

CAMARANO, A. A.; CARVALHO, D. F.; KANSO, S.; MELLO, J. L. As instituições de longa permanência para idosos no Brasil. In: CAMARANO, A. A. (Org.). Cuidados de longa duração para a população idosa: um novo risco social a ser assumido? Rio de Janeiro: Ipea, 2010. p. 187-212.

CAMARANO, A. A.; KANSO, S. As instituições de longa permanência para idosos no Brasil. Revista Brasileira de Estudos de População, São Paulo, v. 27, n. 1, p. 232-235, jan./jun. 2010.

CAMARGOS, M. C. S. Instituições de longa permanência para idosos: um estudo sobre a necessidade de vagas. Revista Brasileira de Estudos de População, São Paulo, v. 31, n. 1, p. 211-217, jan./jun. 2014.

CARVALHO, M. I. L. B. Modelos de política de cuidados na velhice em Portugal e em alguns países europeus. Revista Kairós Gerontologia, São Paulo, v. 12, n. 2, p. 119-133, nov. 2009.

CHAN, A.; MALHOTRA, C.; MALHOTRA, R.; RUSH, A. J.; ØSTBYE, T. Health impacts of caregiving for older adults with functional limitations: results from the Singapore Survey on Informal Caregiving. Journal of Aging and Health, v. 25, n. 6, p. 998-1012, Sep. 2013.

CHRISTOPHE, M.; CAMARANO, A. A. Dos asilos às instituições de longa permanência: uma história de mitos e preconceitos. In: CAMARANO, A. A. (Org.). Cuidados de longa duração para a população idosa: um novo risco social a ser assumido? Rio de Janeiro: Instituto de Pesquisa Econômica Aplicada, 2010. p. 145-162.

CICONELLI, R. M.; FERRAZ, M. B.; SANTOS, W.; MEINÃO, I.; QUARESMA, M. R. Tradução para a língua portuguesa e validação do questionário genérico de avaliação de qualidade de vida SF-36 (Brasil SF-36). Revista Brasileira de Reumatologia, v. 39, n. 3, p. 143-150, 1999.

COUTO, J. A. B. A trajetória ocupacional de cuidadores formais domiciliares de pessoas idosas: gênero, trabalho, qualificação e cuidado. 2012. 189 f. Dissertação (Mestrado) - Universidade de São Paulo, Faculdade de Saúde Pública, Programa de Pós-Graduação em Saúde Pública, São Paulo, 2012.

DAVIM, R. M. B.; TORRES, G. V.; DANTAS, S. M. M.; LIMA, V. M. Estudo com idosos de instituições asilares no município de Natal/RN: características socioeconômicas e de saúde. Revista Latino-Americana de Enfermagem, v. 12, n. 3, p. 518-524, maio/jun. 2004. 
DUARTE, Y. A. O.; BERZINS, M. A. V. S.; GIACOMIN, K. C. Política nacional do idoso: as lacunas da lei e a questão dos cuidadores. In: ALCÂNTARA, G.; CAMARANO, A. A. (Org.). Política nacional do idoso: velhas e novas questões. Rio de Janeiro: Ipea, 2016.

FERREIRA, C. G.; ALEXANDRE, T. S.; LEMOS, N. D. Fatores associados à qualidade de vida de cuidadores de idosos em assistência domiciliária. Saúde e Sociedade, São Paulo, v. 20, n. 2, p. 398-409, 2011.

GARRIDO, R.; MENEZES, P. R. Impacto em cuidadores de idosos com demência atendidos em um serviço psicogeriátrico . Revista de Saúde Pública, São Paulo, v. 38, n. 6, p. 835-841, dez. 2004.

GONZAGA, M. R. O futuro da população brasileira: aspectos metodológicos e operacionais para projeções populacionais no Brasil. Revista Coletiva, n. 13, p. 1-3, jan./abr. 2014.

GROISMAN, D. Formação de cuidadores de idosos: avanços e retrocessos na política pública de cuidados no Brasil. In: MOROSINI, V. G. C.; LOPES, M. C. R.; CHAGAS, D. C.; CHINELLI, F.; VIEIRA, M. (Org.). Trabalhadores técnicos em saúde: aspectos da qualificação profissional no SUS. 1. ed. Rio de Janeiro: EPSJV, 2013. p. 391-419.

IBGE - Instituto Brasileiro de Geografia e Estatística. Síntese de indicadores sociais: uma análise das condições de vida da população brasileira. Rio de Janeiro: IBGE, 2010 (Série Estudos e Pesquisas: informação demográfica e socioeconômica, n. 27).

KAWASAKI, K.; DIOGO, M. J. D. Assistência domiciliária ao idoso: perfil do cuidador formal - parte II. Revista da Escola de Enfermagem da USP, v. 35, n. 3, p. 257-264, 2001 .

Assistência domiciliária ao idoso: perfil do cuidador formal - parte II. Revista da Escola de Enfermagem da USP, v. 35, n. 4, p. 320-327, 2001b.

KUCHEMANN, B. A. Envelhecimento populacional, cuidado e cidadania: velhos dilemas e novos desafios. Sociedade e Estado, v. 27, n. 1, p. 165-180, 2012.

LOPES, R. A.; MITRE, N. C. D.; COELHO, M. A. G. M.; QUEIROZ, B. Z. Perfil dos cuidadores das instituições de longa permanência para idosos de Itaúna - MG. ConScientiae Saúde, v. 11, n. 2, p. 338-344, abr./jun. 2012.

LOUREIRO, L. S. N.; MELO, M. G.; FERNANDES, S. M.; NOBREGA, M. M. L. N.; RODRIGUES, R. A. P. Sobrecarga de cuidadores familiares de idosos: prevalência e associação com características do idoso e do cuidador. Revista da Escola de Enfermagem da USP, v. 47, n. 5, p. 1133-40, 2013.

MEDEIROS, F. A. L. Processo de cuidar em instituições de longa permanência de idosos: (re)pensando a função dos cuidadores. 2014. 162 f. Tese (Doutorado) - Universidade Federal da Paraíba, Centro de Ciências da Saúde, Programa de Pós-Graduação em Enfermagem, João Pessoa, PB, 2014.

MEDEIROS, F. A. L.; OLIVEIRA, J. M. M.; LIMA, R. J.; NÓBREGA, M. M. L. O cuidar de pessoas idosas institucionalizadas na percepção da equipe de enfermagem. Revista Gaúcha de Enfermagem, Porto Alegre, v. 36, n. 1, p. 56-61, mar. 2015.

MOLYNEUX, G. J.; MCCARTHY, G. M.; MCENIFF, S.; CRYAN, M.; CONROY, R. M. Prevalence and predictors of carer burden and depression in carers of patients referred to an old age psychiatric service. International Psychogeriatrics, v. 20, n. 6, p. 1193-202, 2008.

MORAES, E.N. Atenção à saúde do idoso: aspectos conceituais. Brasília: Organização Pan-Americana da Saúde, 2012.

MORALES, R. R.; MORALES, N. M. O.; ROCHA, F. C. G.; FENELON, S. B.; PINTO, R. M. C.; SILVA, C. H. M. Qualidade de vida em portadores de esclerose múltipla. Arquivos de Neuro-Psiquiatria, v. 65, n. 2-B, p. 454-60, 2007. 
Barbosa, L.M. et al. Qualidade de vida relacionada à saúde dos cuidadores formais de idosos institucionalizados...

NAKATANI, A. Y. K.; SOUTO, C. C. S.; PAULETTE, L. M.; MELO, T. S.; SOUZA, M. M. Perfil dos cuidadores informais de idosos com déficit de autocuidado atendidos pelo Programa de Saúde da Família. Revista Eletrônica de Enfermagem, v. 5, n. 1, p. 15-20, 2003.

NICKEL, R.; LIMA, A. P.; NAVARRO, E. J.; PINTO, L. M.; TEIVE, H. A. G.; BECKE, N. Correlação entre a qualidade de vida de cuidadores familiares e os níveis de independência funcional dos cuidados. Cogitare Enfermagem, v. 15, n. 2, p. 225-230, abr./jun. 2010.

OLIVEIRA; S. K.; LANDGRAF, F. J.; DELLAROZA, M. S. G.; YAMADA, K. N.; TRELHA, C. S.; CABRERA, M. A. S. Perfil dos cuidadores de idosos atendidos pelo projeto de assistência interdisciplinar a idosos em nível primário - PAINP - Londrina, PR. Ciência, Cuidado e Saúde, v. 5, n. 2, p. 184-192, maio/ago. 2006.

PALLONI, A.; MCENIRY, M.; DÁVILA, A. L.; GURUCHARRI, A.G. The influence of early conditions on health status among elderly Puerto Ricans. Social Biology, v. 52, n. 3-4, p. 132-63, Fall-Winter 2005.

PALLONI, A.; MCENIRY, M.; WONG, R.; PELAEZ, M. The tide to come: elderly health in Latin America and the Caribbean. Journal of Aging and Health, v, 18, n. 2, p. 180-206, 2006.

PASINATO, M. T. M.; KORNIS, G. E. M. Cuidados de longa duração para idosos: um novo risco para os sistemas de seguridade social. Rio de Janeiro: Ipea, 2009 (Texto para discussão, n. 1371).

PEREIRA, R. A.; SANTOS, E. B.; FHON, J. R. S.; MARQUES, S.; RODRIGUES, R. A. P. Sobrecarga dos cuidadores de idosos com acidente vascular cerebral. Revista da Escola de Enfermagem da USP, v. 47, n. 1, p. 185-192, 2013.

PINTO, S. P. L. C.; SIMSON, O. R. M. V. Instituições de longa permanência para idosos no Brasil: sumário da legislação. Revista Brasileira de Geriatria e Gerontologia, Rio de Janeiro, v. 15, n. 1, p. 169-174, 2012.

PINTO, M. F.; BARBOSA, D. A.; FERRETI, C. E. L.; SOUZA, L. F.; FRAM, D. S.; BELASCO, A. G. S. Qualidade de vida de cuidadores de idosos com doença de Alzheimer. Acta Paulista de Enfermagem, v, 22, n. 5, p. 652-657, 2009.

POLLO, S. H. L.; ASSIS, M. Instituições de longa permanência para idosos - ILPIS: desafios e alternativas no município do Rio de Janeiro. Revista Brasileira de Geriatria e Gerontologia, v. 11, n. 1, p. 1-18, 2008

RIBEIRO, M. T. F.; FERREIRA, R. C.; FERREIRA, E. F.; MAGALHÃES, C. L.; MOREIRA, A. N. Perfil dos cuidadores de idosos nas instituições de longa permanência de Belo Horizonte, MG. Ciência e Saúde Coletiva, Rio de Janeiro, v. 13, n. 4, p. 1285-1292, ago. 2008.

RIBEIRO, M. T. F.; FERREIRA, R. C.; MAGALHÃES, C. S.; MOREIRA, A. N.; FERREIRA, E. F. Processo de cuidar nas instituições de longa permanência: visão dos cuidadores formais de idosos. Revista Brasileira de Enfermagem, v. 62, n. 6, p. 870-875.

RIBEIRO, R. N. Cuidador de idoso: discussão do processo de regulamentação da profissão pela análise discursiva de audiências públicas. 2015. 189 f. Tese (Doutorado) - Universidade de São Paulo, Instituto de Psicologia, São Paulo, 2015.

RIPSA - Rede Interagencial de Informações para a Saúde. Demografia e saúde: contribuição para análise de situação e tendências. Brasília, 2009.

ROCHA, A. S. Custos com benefícios para o financiamento com cuidados de longa duração para idosos com dependência: estimativas e projeções para o Brasil. 2015. 273 f. Tese (Doutorado) - Universidade Federal de Minas Gerais, Centro de Desenvolvimento e Planejamento Regional, Programa de Pós-Graduação em Demografia, Belo Horizonte, 2015.

SAAD, P. M. Transferência de apoio intergeracional no Brasil e na América Latina. In: CAMARANO, A. A. (Org.). Os novos idosos brasileiros: muito além dos 60? Rio de Janeiro: Ipea, 2004. p. 169-210. 
Barbosa, L.M. et al. Qualidade de vida relacionada à saúde dos cuidadores formais de idosos institucionalizados...

SANTOS, A. A.; PAVARINI, S. C. I. Perfil dos cuidadores de idosos com alterações cognitivas em diferentes contextos de vulnerabilidade social. Revista Gaúcha de Enfermagem, Porto Alegre, v. 31, n. 1, p. 115-22, mar. 2010.

SILVA, I. L. S.; MACHADO, F. C. A.; FERREIRA, M. A. F.; RODRIGUES, M. P. Formação profissional de cuidadores de idosos atuantes em instituições de longa permanência. HOLOS, ano 31, v. 8, p. 342-356, jan. 2016.

SIMONETTI, J. P.; FERREIRA, J. C. Estratégias de coping desenvolvidas por cuidadores de idosos portadores de doença crônica. Revista da Escola de Enfermagem da USP, São Paulo, v. 42, n. 1, p. 19-25, mar. 2008.

TURRA, C. M. Os limites do corpo: a longevidade em uma perspectiva demográfica. Revista da UFMG, n. 19, p. 156-181, 2012.

VASCONCELOS, M. Responsabilidades familiares. Revista do Observatório Brasil da Igualdade de Gênero. Primeira Impressão. Brasília: Secretaria Especial de Políticas para as Mulheres, p. 36-43, 2009.

VERAS, R. P. Em busca de uma assistência adequada à saúde do idoso: revisão da literatura e aplicação de um instrumento de deteç̧ão precoce e de previsibilidade de agravos. Cadernos de Saúde Pública, Rio de Janeiro, v. 19, n. 3, p. 705-715, maio/jun. 2003.

Envelhecimento populacional contemporâneo: demandas, desafios e inovações. Revista de Saúde Pública, São Paulo, v. 43, n. 3, p. 548-554, maio-jun. 2009.

WARE, J. E.; SHERBOURNE, C. D. The MOS 36 Item Short-Form Health Survey (SF-36). I. Conceptual framework and item selection. Medical Care, v. 30, n. 6, p. 473-483, 1992.

WONG, L. L. R.; CARVALHO, J. A. M. O rápido processo de envelhecimento populacional do Brasil: sérios desafios para a saúde pública. Revista Brasileira de Estudos de População, São Paulo, v. 23, n. 1, p. 5-26, jan-jun. 2006.

\section{Sobre as autoras}

Lara de Melo Barbosa é doutora e mestre em Demografia pela Universidade Federal de Minas Gerais (UFMG). Professora associada III do Departamento de Ciências Atmosféricas e Climáticas da Universidade Federal do Rio Grande do Norte (UFRN) e coordenadora do Programa de Pós-graduação em Ciências Climáticas da UFRN.

Kenya Noronha é doutora e mestre em Economia pelo Centro de Desenvolvimento e Planejamento Regional (Cedeplar) da Universidade Federal de Minas Gerais (UFMG). Professora do Departamento de Economia e do Cedeplar da UFMG. É vice-coordenadora do Grupo de Estudos em Economia da Saúde e Criminalidade (GEESC) no CNPq.

Maria Helena Constantino Spyrides é doutora em Saúde Pública pela Fundação Oswaldo Cruz (Fiocruz) e mestre em Agronomia (Estatística e Experimentação Agronômica) pela Universidade de São Paulo (USP). Professora adjunta no Departamento de Estatística da Universidade Federal do Rio Grande do Norte (UFRN) e do Programa de Pós-graduação em Ciências Climáticas (Mestrado e Doutorado).

Cristiane Alessandra Domingos de Araújo é doutoranda em Demografia no Centro de Desenvolvimento e Planejamento Regional (Cedeplar) da Universidade Federal de Minas Gerais (UFMG) e mestre em Demografia pelo Programa de Pós-graduação em Demografia da Universidade Federal do Rio Grande do Norte (UFRN). 


\title{
Endereço para correspondência
}

\author{
Lara de Melo Barbosa \\ Universidade Federal do Rio Grande do Norte - Centro de Ciências Exatas e da Terra, s/n, \\ Lagoa Nova \\ 59078-970 - Natal-RN, Brasil \\ Kenya Noronha \\ Universidade Federal de Minas Gerais - Faculdade de Ciências Econômicas \\ Avenida Presidente Antonio Carlos, 6627, Pampulha \\ 31270-901 - Belo Horizonte-MG, Brasil \\ Maria Helena Constantino Spyrides \\ Universidade Federal do Rio Grande do Norte - Centro de Ciências Exatas e da Terra, s/n, \\ Lagoa Nova \\ 59078-970 - Natal-RN, Brasil \\ Cristiane Alessandra Domingos de Araújo \\ Avenida Paulo Afonso, 1750 Bloco I, Apto. 103 \\ 59146-020 - Parnamirim-RN, Brasil
}

\begin{abstract}
Health-related quality of life of formal caregivers of the institutionalized elderly in Natal, Rio Grande do Norte
\end{abstract}

Brazil has experienced an aging population process that poses challenges to meet the needs of the elderly group, especially those with functional limitations. In this scenario, Long-Term Care (LTC) institutions for the elderly can be important to provide support and help to this population group and their families. The aim of this paper is to characterize the profile of the formal caregivers in LTC institutions. More specifically, this paper addresses the health-related quality of life (HRQoL) of this population group measured by the SF-36 instrument. Sociodemographic and occupational profile of these individuals is also discussed. The data come from a survey carried out in 2012 among the formal caregivers employed in 11 of the 12 ILPI registered in Natal, RN. Ninety two formal caregivers were interviewed and they represent $68 \%$ of the total universe of this group in the city. Descriptive analysis and statistical tests to verify differences between philanthropic and private institutions are provided. The greatest loss of HRQoL was observed for the general health perceptions dimension followed by vitality and bodily pain domains. The loss of HRQoL may reflect the excessive workload imposed on caregivers related to both working hours and the high number of elderly people under the responsibility of each caregiver. Non statistically significant differences were observed in the HRQoL between philanthropic and private institutions.

Keywords: Aging population. Formal caregivers of the elderly. Long-term care institutions. SF-36. Health-related quality of life. 


\section{Resumen}

Calidad de vida relacionada con la salud de los cuidadores formales de personas mayores institucionalizados en Natal, Rio Grande do Norte

Brasil está experimentando un proceso de envejecimiento de la población que plantea desafíos para satisfacer a las necesidades de las personas mayores, sobre todo los dependientes funcionales. Instituciones de larga permanencia (ILP) para adultos mayores pueden ser una opción de ayuda y apoyo a este grupo de la población y sus familias. El objetivo de este artículo es caracterizar el perfil del cuidador de los ancianos institucionalizados y específicamente abordar la calidad de vida relacionada con la salud (CVRS) basado en el SF-36. También se analizó el perfil sociodemográfico y laboral de estas personas. Los datos provienen de una encuesta realizada en 2012 entre los cuidadores formales ocupados en 11 de las 12 ILP registradas en Natal, RN. Se entrevistó a 92 cuidadores formales, lo que representa el $68 \%$ del universo. Se realizaron análisis descriptivos y pruebas estadísticas para verificar las diferencias entre las instituciones filantrópicas y privadas. La mayor pérdida de la CVRS se observó para la dimensión de las percepciones de la salud general, seguida por los dominios de la vitalidad y dolor. La pérdida de la salud puede, en cierta medida, reflejar la mayor carga de trabajo impuesta a los cuidadores, tanto en relación con las horas de trabajo, así como el elevado número de adultos mayores bajo la responsabilidad de cada cuidador. No se observaron diferencias significativas en la CVRS entre las instituciones filantrópicas y privadas.

Palabras clave: Envejecimiento. Cuidadores de adultos mayores. Instituciones de larga permanencia. SF-36. Calidad de vida relacionada con la salud.

Recebido para publicação em 02/08/2016 Aceito para publicação em 08/06/2017 